\title{
Flitse van sosiale verandering in enkele postmodernistiese Afrikaanse romans
}

\author{
D.H. Steenberg \\ Departement Afrikaans en Nederlands \\ Potchefstroomse Universiteit vir $\mathrm{CHO}$ \\ POTCHEFSTROOM
}

\begin{abstract}
Glimpses of social change in some postmodernist Afrikaans novels

Postmodernist novels, and thus also Afrikaans postmodernist novels, are radically anti-traditional. In one respect, however, they maintain the tradition of Afrikaans fiction: they open perspectives on the development of the society from which they originate. Functioning in a multicultural community, the novelists' awareness often concerns the development of relations between different racial groupings in the South African society, which is seen as basically African. The breaking down of the (colonial) barriers between black and white by writers of historiographic metafiction like John Miles and André Letoit - can perhaps be regarded the first step in the direction of social transition. Letoit hails Africa as the continent of promise, and authors like Berta Smit, Eben Venter and Etienne van Heerden present visions of a growing harmony between black and white in the new South Africa.
\end{abstract}

\section{Belowende andersheid}

Afrikaanse romans open inderdaad interessante perspektiewe op die ontwikkeling van die gemeenskap waarin hulle ontstaan het. Dit is waar van die 19de-eeuse koloniale literatuur van C.P. Hoogenhout, S.J. du Toit en veral van Sewe duiwels en wat hulle gedoen het van Jan Lion Cachet - literatuur wat fokus op die 'sondes' in die gemeenskap. Hierdie tradisie word voortgesit in die Afrikaanse prosa van die twintigste eeu - sowel die vroeër landelike prosa as latere stedelike prosa van ná 1960 .

Die ontplooiing van die verhouding tussen Suid-Afrikaanse rassegroepe vind in ooreenstemming hiermee toenemend neerslag in Afrikaanse romans. Die verandering wat die saambestaan van verskillende kulturele groepe in die veranderende Suid-Afrikaanse gemeenskap raak, is inderdaad af te lees uit die Afrikaanse prosa - produkte van 'n minderheidsgroep maar toeganklik vir 'n breë leserskorps. In 'n proefskrif oor die Afrikaanse roman voor 1948 bevestig Jakes Gerwel by implikasie hierdie stelling, waar hy verwys na die "hoofsaaklik 
ondersteunende rol wat die letterkunde in die ontwikkeling tot amptelike Apartheid gespeel het" (Gerwel, 1983:206). Sedertdien is die proses taamlik drasties omgekeer, en min of meer 'n kwart eeu lank - sedert 1960 - het Afrikaanse romans stem gegee aan die protes teen apartheid.

'n Belangrike uitvloeisel van hierdie andersheid van die nuwer Afrikaanse prosa is die bewustheid wat te bespeur is by romansiers uit die hoofstroom van die Afrikaanse prosa aan die einde van die tagtigerjare van die belangrike rol van die kuns in lewensvernuwing. Die bewustheid van die skeppende rol wat die kuns in die transformasieproses in 'n nuwe bedeling kan speel, stem ooreen met die volgende stelling van Patricia Waugh (1992:19), waarin sy die Postmodernisme met die Romantiek vergelyk: "Romantic and postmodern thought (are) modes which, in different ways, privilege art and give it a central place in the organisation of human experience". Die kuns is immers vir haar 'n vorm van liggaamlike ervaring (Waugh, 1992:19).

In sommige resente romans kom hierdie tendens neer op die herlewing van estetisisme, naamlik ontvlugting in die kuns, onder andere in die beeldende kunste, soos by Leonie, die hoofkarakter in Wolftyd, 'n tydgenootlike roman van Anna M. Louw (1991), maar ook ontvlugting in die woordkuns, soos by Griet, die hoofkarakter in Marita van der Vyver se roman Griet skryf 'n sprokie (1992). Sommige romantekste, soos Suidpunt-jazz (1989) van André Letoit en Juffrou Sophia vlug vorentoe van Berta Smit (1993), gee 'n visie op sosiale vernuwing deur middel van 'n metatekstuele aanbod van hulle romantekste.

Die doel van hierdie artikel is om te fokus op die inkleding van relevante menslike ervaring in enkele Afrikaanse romans, in besonder op die voorstelling van lede van vervreemde bevolkingsgroepe se veranderende lewensomstandighede. Die postmodernistiese inslag van die sterkste vernuwende stroom in die Afrikaanse prosa, sowel as die fokus wat in verskeie romans op die sosiale verandering in Suid-Afrika van die negentigerjare val (dit wil sê op die afbreek van sosiale grense), maak dit dubbeld wenslik dat aanduidings van hierdie verandering (oorgang?) onder die loep geneem word. Van die voorstelling van verandering in romans (hoewel insonderheid op politieke vlak) maak Michiel Heyns (1994:62) reeds gewag na aanleiding van Casspirs en Campari's van Etienne van Heerden en An Act of Terror van André P. Brink. Heyns meen "both works span the most significant hiatus in recent South African history". In hierdie artikel wil ek ander romans as Heyns bespreek, naamlik Juffrou Sophia vlug vorentoe (Berta Smit), Die stoetmeester (Etienne van Heerden) en Foxtrot van die vleiseters (Eben Venter). In my benadering van hierdie romans wil ek minder klem lê op die politiese, en eerder let op die sosio-ekonomiese afstande (grense?) wat van 'n koloniale gemeenskapsordening oorgebly het. 
Met die afbakening van so 'n probleem oor die roman raak jy inderdaad die kern van verhalende literatuur aan - as jy immers dink aan Arthur Danto (1985:70) se omskrywing van "narrative" as "an explanatory account of changing, coherent past events". Van Zyl (1993:236) vereenselwig hierdie verandering met die dinamiek van ordening in die tyd, met kousale verbande en met 'n duidelike voortgang, naamlik "continuity on the level of ... subject matter". So 'n voortgang veronderstel 'n sekere konstantheidsvlak van inhoudelike gegewe ("subject matter"), wat neerkom op ' $n$ redelik konstante identiteit oor die hele linie van die komponente van die roman - 'n identiteit wat ook verander. 'n Roman is of bevat dus 'n reeks gebeuremomente maar ook 'n sekere herkenbare identiteit(e), naamlik die ruimte, wêreldbeeld, karakters, gerepresenteerde sosiale orde en profiel van die gemeenskap waarna die teks verwys. As Van Zyl $(1993: 2,37)$ dan die roman sien as "explanatory account of changing, coherent past events", impliseer dit dat hierdie veranderings in historiografiese fiksie neerslag vind, en hierdie fiksie die gedaante aanneem van kulturele geheue. In 'n multikulturele, trouens veelrassige gemeenskap, is dit logies dat meer as een roman sal fokus op die veranderende verhouding tussen die onderskeie bevolkingsgroepe soos dit in die roman gestalte vind.

\section{Verandering en revisionisme ${ }^{1}$}

Reeds in 1983 demitologiseer John Miles die tradisionele Suid-Afrikaanse geskiedenis in sy roman Blaaskans. By monde van sy karakter, Flip Nel, ondergrawe hy die teorie van die geskiedenis van die Groot Ideaal, waarvolgens herinnering geskiedenis word. Hy formuleer dan 'n eietydse siening van historisiteit, naamlik dat geskiedenis gesien word as interpretasie, maaksel van die historikus (beredeneer in Steenberg, 1996:189). Soos 'n ontdekker van 'n nuwe wêreld stel die abstrakte outeur van Blaaskans 'n nuwe ideaal vir sy benadering van taal en die begryp van sy wêreld: 'n mens moet die gegewens agter die taal blootlê, en sal nooit die einde daarvan sien nie - sy manier om die postmodernistiese strategie van différance (uitstel van betekenis) te formuleer (Steenberg, 1996:189). "Sal nooit die einde daarvan sien nie" is 'n manier om te stel dat betekenis ontwykend van aard is en dat geen betekenis wat aan 'n teken toegeken word, ooit finaal kan wees nie.

1 Hierdie artikel is 'n voortsetting van bydraes tot konferensies in 1991 en 1993, wat respektiewclik gepubliseer is as Stcenberg 1991 en Steenberg 1996. Hierdie bydraes handel oor revisionisme en verandering in Suid-Afrika, wat indertyd op die voorgrond was in enkele romans en hier ook relevant is vir die oorgang in sosiale verhoudinge waarheen die klem sedertdien verskuif het. In laasgenoemde artikel toon ek aan dat Afrikaanse skrywers van historiografiese metafiksic (term van Linda Hutcheon, 1988:5), naamlik André Letoit en John Miles, nuwe visies copslaan op historiese gegewens (in die besonder gebeure) en die rolle van tradisionele helde wat daarby betrokke was. 
In Suidpunt-jazz (1989) demitologiseer André Letoit die tradisionele geskiedenis van die Volksplanting aan die Kaap en van die Groot Trek deur die name van tradisionele helde saam te noem en die heldefigure by implikasie gelyk te stel met bekende lewende persone. Die vergelyking word telkens op grond van 'n enkele raakpunt tussen die twee figure gemaak, natuurlik met satiriese en/of bloot humoristiese effek. Enkele persone wat vergelyk word (Letoit, 1989:161, 162) is Rageltjie de Beer met Zola Budd, Simon van der Stel met Nataniël, Piet Retief met André Letoit en Sarel Cilliers met Biskop Tutu, ensovoorts.

In hierdie voorstelling verwys Letoit na Truwella Cameron se The New History of South Africa, en aanvaar hy by implikasie inderdaad haar dinamiese hantering van die geskiedenis oor die algemeen, en die geskiedenis van Suid-Afrika in die besonder (Steenberg, 1996:189). In 'n evaluering van die vernuwing van die geskiedskrywing klassifiseer L.W.F. Grundlingh (1989:33) Cameron by implikasie by die revisioniste onder die historici op grond van haar "soeke en begeerte na meer relevante en opwindende geskiedenis", in die sin dat sy in haar boek "sommige tradisionele beskouinge oor die Suid-Afrikaanse geskiedenis geînterpreteer het".

Met hulle postmodemistiese strategieë lê Miles en Letoit by wyse van spreke die siening van geskiedenis van die Groot Ideaal en die ooreenkomstige siening van die geskiedenis van die staatkundige en volksontwikkeling van die blankes in Suid-Afrika af en berei hulle die weg voor vir 'n benadering van die verhouding tussen groepe mense in Suid-Afrika in ooreenstemming met die siening van die geskiedenis as interpretasie of maaksel van die historikus. Daarmee het Miles en Letoit 'n hipotese van Jacques Derrida sin gegee: skryfwerk berei die weg voor vir die ontplooiing van die geskiedenis ("writing opens die field ... of historical becoming" - Derrida, 1976:27, aangehaal deur Steenberg, 1996:192). Hierdie historiese ontwikkeling wat in die genoemde romans voorgestel word, het in Afrikaanse romans gewoonlik 'n noue samehang met 'n Europees-georiënteerde perspektief op Afrika en mense/karakters van inheemse Afrika-oorsprong. Die Afrika-motief figureer byvoorbeeld sterk in Suidpunt-jazz van André Letoit.

\section{Afrika, kontinent van belofte}

Die toekomsflitse oor Afrika in Suidpunt-jazz vorm positiewe teenpole vir die gedemitologiseerde tradisionele geskiedenis met sy gedekonstrueerde galery van helde. Met aansteeklike optimisme flits die Letoit-verteller 'n beeld van Natal, "sonder vrees en sonder dood" (p. 120) ${ }^{2}$ en van Afrika, saamgesnoer deur 'n

2 Syfers tussen hakies verwys na bladsynommers in die teks onder bespreking 
wetboek "wat vrede sal maak tussen wit en swart" (p. 121). Dit is klaarblyklik 'n postkoloniale beeld van hierdie vasteland

... (w)ant Afrika behoort slegs aan homself en hoef voor niemand te kniel nie, hoef aan niemand verantwoording te doen nie. Afrika teken sy eie landkaarte, bepaal sy eie grense, dien sy eie gode, stook sy eie vure, bemin sy eie vroue, dans sy eie danse. Ja, Afrika sal sy verskeidenheid van volke, kleure en broers één maak! Afrika sal skoon soos 'n roos in die tuin van die Skepper van vuur en water en rook en trane wees. Skoon soos die siele wat nie rus van al hulle goedheid nie (p. 122).

Hierdie optimisme word egter ver oortref deur die toekomsvisie wat voorgestel word as profesie wat die ou Indoena van die 'teks' van sy dolosse aflees:

Van oor die hele wêreld sal mense na Afrika toe stroom om heil te soek, om hulle sterwende helde en gode te red, om waardes te kom haal en terug te neem in groot kalbasse. ... Hulle sal nie meer kom om óns te leer nie, maar ons sal húlle leer van die dinge wat hulle so slim was om te vergeet tussen die omslae van té veel boeke en té baie twyfel. Ons sal hulle leer om miershope oop te breek op soek na ware goud ... Ons sal hulle leer wie ons is en wie hulle is, en dat ons almal een is op hierdie wêreld, van nou af tot in ewigheid (p. 93).

Veral laasgenoemde eenheidsvisie gee aan hierdie Afrika-flitse 'n sterk apokaliptiese karakter. Min eietydse lesers sal hierdie flitse anders ervaar as erg optimisties. Tog moet dit gelees word as 'n baanbrekende visie van wat kan wees en moontlik minstens deur 'n sektor van die bevolking vertroetel word. Die gedagte aan "ons almal een" spreek ook van 'n sterk houding van vereenselwiging met almal wat van Afrika is. Relevant is dan om te vra hoe diep hierdie gesindheid van vereenselwiging gewortel is of hoe ver dit strek en oor hoeveel en watter grense heen.

\section{Vereenselwiging met jou medemens / afbreek van sosiale grense}

Dit is 'n bekende tendens, soos Appiah (1991:342) dit stel, dat postmoderniste "prefer to produce art according to the need for distinctions in the market" - die resultaat van "a certain intensification of the long-standing individualism of a post-Renaissance art of production: in the age of mechanical reproduction". Appiah (1991:344) sien daarin die teenoorgestelde van Verligting en rede, naamlik "charisma and the universalization of the secular: ... the incorporation of all areas of the world and all areas of even formerly 'private' life into the moneyeconomy ... (M)odernity (lees: Die skrywer van ons tyd, met al sy verworwe vaardighede te danke aan die Modernisme - DHS) has turned every element of the real into a sign, and the sign reads 'for sale'." 
Die aanwesigheid van tegnologiese sisteme vir massareproduksie in 'n tyd van toenemende weerstand teen die elitisme van die modernistiese literatuur - in besonder in Afrikaans - skep 'n scenario vir anti-elitisme en 'n dienooreenkomstige 'demokratisering' van resente Afrikaanse prosawerke. Dit loop uit op teksgenerering vir die massas Afrikaanssprekendes (en -lesendes), wat 'n groot diversiteit vertoon. As kreatiewe versoening tussen eie en ander kulture kan hierdie byna perkelose popularisering - "ongelisensieerde metafisika in 'n teekoppie" soos Annie Dillard (1982:11) dit noem - 'n positiewe uitreik na die minder bevoorregte miljoene van Suid-Afrika beteken. Dit is juis die outeur van Suidpunt-jazz (Letoit, 1989:18) se intensie om "'n laken van begrip (te) span, 'n laken om oor die hele volk te span sodat hulle kan lees".

By implikasie word hierdie intensie van Letoit bevestig deur sy populêre styl, en bring dit reeds 'n klemlegging op tradisionele grense tussen groepe mense mee, naamlik tussen hoër en laer sosiale klasse sowel as tussen rasse. Inderdaad stem hierdie bewusmaking van tradisionele grense ooreen met die strewe na verskille of andersheid wat Appiah (1991:342) aan postkoloniale Afrika-kuns toeskryf: "To sell oneself and one's products as art in the market-place, one must, above all, clear a space in which one is distinguished from other producers and products - one does this by the construction and the marking of differences." In die kader van hierdie "retheorization of the proliferation of distinctions" (Appiah, 1991:346) pas die aanslag op die erfenis van rasseverhoudinge wat in die gekose tekste gemaak word, volkome in. In hierdie "marking of differences" soos 'n mens vernuwings soos hierdie na aanleiding van Appiah se stelling (hierbo) kan noem, vloei postkolonialisme en postmodernisme saam. Hierdie strewe om deur nuwe oë na die bestaande of heersende te kyk word inderdaad ikonies in Suidpunt-jazz van André Letoit verwesenlik.

In die skrywerkarakter André se nuwe boek waaroor in Suidpunt-jazz gerapporteer word, word 'n swart man as verteller aan die woord gestel met die doel om deur sy oë na rassebetrekkinge te kyk. Die swart verteller ontmoet 'n wit meisie in 'n derderangse restaurant in Hillbrow (p. 159):

Ons sit in 'n derderangse eetplek in Hillbrow. Voor my sit sy, die meisie wat ek na soveel jare se soek opgespoor het: Isis van Afrika. Sy is blond, donkerige blonde hare, met 'n wit vel. Sy is geklee in 'n swart rok. Op haar kraag is 'n lapelwapentjie wat lui 'Born to shop'. Sy sit en speel met haar Coke-strooitjie terwyl sy stadig, lui-lui praat: 'Ek weet nie of dié verhouding veel langer sal hou nie. Vir 'n hele ruk het ons albei reeds die gevoel dat ons nie by mekaar pas nie. Dink jy nie ook so nie?'

Ek kyk af na my swart hande, na die toiings van my baadjiepante, en praat met my skewe aksent in die taal wat ek reeds jare terug gedeeltelik 
bemeester het, maar nou nog vreemd op die tong vind: 'Wel, ja. Maar at least die wet hy is nie meer teen ons nie.'

Sy sug: 'Afrika, ek pas nie by jou nie. Ons luister nie na dieselfde musiek nie. Ons lees nie dieselfde boeke nie. Ons deel nie dieselfde sporthelde nie. Ek is mal oor Naas Botha, en jy ... wel, jy sien self ek weet nou nog nie eens hoeveel spelers in een sokkerspan speel nie. Daar is geen toekoms vir ons nie, liefling.'

'Ons het nog nooit liefde gemaak nie,' sê ek treurig. 'nie eers één zap-zap nie. Hoe weet ons voor ons dit nie probeer het nie?'

'En ons kinders? Wat gaan van hulle word?' Die onsekerheid, die angs in haar oë is te ongelooflik om in woorde van enige taal te beskryf.

Ek kyk diep in haar oë en my woorde kom met skor snikke uit.

'Bloed hoort by oorlog, miesies,' pleit ek, 'en hierdie is g'n oorlog nie. Bloed hoort by soldate, by skiet en veg vir vryheid. Nie in hierdie restaurant nie. Nie nou nie. Ons het mos klaar gevind, dié deng waarvoor ons voorvaders so hard gebaklei het.'

Sy haal haar beursie uit om te betaal vir ons twee. 'En wat is dit miskien?' vra sy, nog skepties.

'Vir die reg miesies,' sê ek verlig, 'vir die reg van alle mense in ons land om mekaar beskaaf te haat. Vir die reg van alle mense, ongeag kleur, om deur die week soos witmense te werk en oor die naweek soos kaffers te suip en musiek te maak.'

Sy staan op, vee 'n blonde krul van haar oë weg. 'Ek het vyfhonderd jaar te vroeg opgedaag, sê sy. 'Maar ek sal sien wat ek kan doen.'

So loop die eksperiment van Letoit om swart en wit persone van die teenoorgestelde geslag saam te voeg uit op 'n situasie vol swart humor.

Op haar beurt word die vertellerkarakter in Juffrou Sophia vlug vorentoe van Berta Smit geïnspireer deur die historikus Johnson (A History of the Modern World) se vraag oor die moontlikheid van saambestaan van hoër en minder ontwikkelde groepe: "Is it possible to extend a higher civilization to the lower classes without debasing its standard and diluting its quality to the vanishing point? Is not every civilization bound to decay as soon as it begins to penetrate the masses?" (p. 21).

Smit se kreatiewe reaksie in die metateks van haar roman kom neer op 'n ontkennende antwoord op Johnson se besonder ideologies gelaaide retoriese vraag. Haar positiewe voomeme stem ooreen met dié van Letoit: "Ek wil so 
graag 'n roman skryf, 'n storie ... oor die haat, die vervreemding tussen mense, en hoe ons weer met mekaar versoen kan word" (p. 203). Vanuit die Christelike standpunt wat sy inneem, stel sy 'n hoë doelwit vir haar roman: "My roman moet 'n boodskap van hoop bring, ... 'n droom vir die toekoms - nuwe pad vorentoe" (p. 151). En binne haar konteks ondergaan juffrou Sophia 'n innerlike metamorfose. Haar veranderde houding teenoor haar bruin bediende, Mavis, blyk nie net uit haar nuwe aanspreekvorm vir "Mavis! ... My kind!" (p. 242) nie, maar ook in haar simpatieke optrede teenoor haar getroue werknemer. Haar besorgdheid lei daartoe dat sy op 'n dag Mavis se nat trui afstroop en, soos vir 'n baba, haar eie oranje toeknooptrui vir Mavis aantrek, en in die proses bewus word van die skoonheid van Mavis se velkleur: "Die mou is te kort. Maar die kleur! Die helder oranje van die wol laat haar okerbruin gesig gloei met 'n nuwe, boeiende lewe" (p. 243).

Ten spyte van die aanranding op Mavis deur haar eie vriendin, Charlene, tree juffrou Sophia meelewend op in die soektog na die verdwene Charlene en troos haar met die vergiffenis van Christus (p. 252):

... jy sal nie nodig hê om te bloos nie hoor daar Issa Charlene luister asseblief hoor daar Hy roep jou ek sê namens Hom ek sy verteenwoordiger op aarde sy erfgenaam ek het vir julle 'n boodskap van Hom hoor daar luister fyn spits jou ore Hy roep julle by die naam Issa liewe kind kom Issa kom Charlene kom proe die soet smaak van sy vergiffenis ...

Van ' $n$ haas onoorbrugbare kloof tussen twee duidelik herkenbare groepe (aanvanklik "ons" en 'n bedreigende groep, 'n "verneuknasie") maak ook Eben Venter se Foxtrot van die vleiseters (1993:12) gewag. Petrus Steenekamp vertel van die vrese van blankes op die Suid-Afrikaanse platteland. Hy beskryf ' $n$ skare by ' $n$ landbouskou eers in Ouma Lalie se personeteks:

“'Al gaan ons ook in 'n dal van doodskaduwee', prewel ouma Lalie". Dan volg by monde van die verteller self:

Verby die pawiljoen en die tuisvlytsaal, verby die perdestalle ... vee die wind die stukkies mens wat ' $n$ leeftyd in dieselfde dorp geloop en gekoop het, leeftye van stukkies mens uit die lendene van hulle oumas en oupas en grootjies en geslagte van mense wat almal saam grootgewond het hier op die vlaktes en tussen die rantjies saam met die springbokke en die dassies en die aasvoëls, en nog altyd, en vir ewig, hys die ou vrees hom maar weer op in ons oë. Net so onontwykbaar soos die verskrikking wat die gogga vir die baba inhou. En nooit, God wees ons kleingeestiges genadig, sal dit anders wees nie (p. 189).

Venter rapporteer sekere ironiese hoogtepunte in die verhoudinge tussen wit en swart op die platteland: ' $n$ 'verkragting' met toestemming tussen twee jongmense 
wat nie mekaar se tale verstaan nie; nie-gewelddadige konflik tussen wit boer en swart werker, en die treurigheid van die afskeid tussen twee gesinne (wit en swart) wat jare lank naby mekaar gewoon en gewerk het. Hierdie afskeid laat die swart werker so arm soos altyd.

Die belangrikste is egter die sensitiwiteit waarmee die verteller die toestand van die arm plaaswerkers voorstel: 'n ou vader en twee meisies: een, Buziwe, die ouderdom van die verteller, Petrus Steenekamp, self. Die gedepriveerde mense moet byvoorbeeld vanweë hulle gebrek aan 'n eie vervoermiddel in ' $n$ "ysige nag" buite in winterkoue op 'n oop bakkie sit en wag terwyl hulle werkgewergesin 'n skoolopvoering van $A$ sound of music bywoon. Hieroor bieg Petrus Steenekamp wanneer hy in sy ryper jare die situasie herbeleef:

Hulle het daardie dag saam met ons dorp toe gery vir inkopies. En vir die duur van die konsert agterop die bakkie gesit sodat hulle weer saam met ons kan terugry plaas toe. God vergewe my, pleit ek toe ek die bondel verkluimdes op die bakkie gewaar. Vergewe my die jas aan my lyf, my handskoene, vergewe my die wolkouse aan my voete, my langmoufrokkie, onder my flennie-winterhemp, vergewe, o God, my woltrui. Die voorportaal van die stadsaal, kon hulle nie daar gewag het nie? (p. 223).

Die hoop van die meelewende waarnemer is op die jeug gevestig. Petrus, die jongste Steenekamp-kind en tipiese sensitiewe buitestander, word bewus daarvan dat Buziwe, die dogter van oupa Dzozo, die swart plaaswerker, vir oulaas met hom wil praat voor hulle vertrek ná haar vader se ontslag:

Buziwe met haar bruin bokoë ... (e)k kan raai dat sy van my teenwoordigheid in die stal te hore gekom het. Dit lê al aan die sagte bewing as sy so stip na my kyk. En dis nog iets, sy kyk na my. En ek na haar. Asof ons vir die laaste keer iets van mekaar verwag voordat sy van Wildeperdehoek af skoert. 'n Enkel woord, 'n goedigheid langs die mondhoeke, die gebaar van 'n oop hand, 'n flits van aanraking. Sy om my vry te koop van al hierdie jare wat ek alles op Wildeperdehoek gesien en ... ervaar het ... $\mathrm{Al}$ daardie dae en nagte van aantekeninge maak oor hulle oë ... Al daardie ure wat ek gewy het aan notas oor oplossings ... (p. 205).

Foxtrot van die vleiseters word 'n uittreksel uit die verslae wat Petrus opgestel het oor die ontbering van oorlewing op R76 per maand se rantsoene (p. 206), van bitter koue en min besittings en uitgesit te wees op die trekpad met skaars 'n uitsig op 'n heenkome vorentoe. Daarvan getuig Petrus, en vestig sy hoop op Buziwe om hom vry te koop van die "dialektiese situasie" (p. 206) dat juis die werk van Xhosa-"waterdraers en -pakesels" dit vir hom moontlik gemaak het om sy notatjies, "al die afskuwelikhede, in drukskrif tydelik neer te skryf en te bedink" (p. 206). 
Daarom neem hy haar, uitgevat in sy suster se swemklere, na die nabygeleë warmbron om te gaan swem. Terwyl kleinboet Hennie protesterend in die bakkie wag, neem hy Buziwe die water in. In die water speel hulle tipiese meisie-seunspeletjies. Hy sien egter in 'n fantasieflits 'n skrikbeeld van sy moeder, Iris Steenekamp, eers in die rooi kannas langs die bron en later wydsbeen op die buurvrou se mak haan op 'n wolk en met 'n boek en 'n .22 dreigend in die hand: “... ek skryf alles op, Petrus, de laaste ding, sê sy. En in haar hand is die .22: ek kom my kind nou self haal, Petrus. Ek wou jou nog altyd vertrou ..." (p. 219).

Terselfdertyd verskyn 'n skrikbeeld van Petrus se vader, Hendrik Steenekamp, agter hom, "lomp so in die water met sy kerkpak, hemp en das", terwyl hy skel: "Jou verdomde klein verraaier, Petrus ... saam met een van ons meide in die swembad. Ek skaam my net om dit te sê" (p. 219).

Die outeur se voorstelling van Petrus en Buziwe se samesyn in die warmbron bevestig by implikasie die sosiale grens tussen wit en swart. Sy vrees vir twee van die gesagdraers in sy gesin, naamlik sy vader en sy moeder, illustreer die sterk tradisiegeoriënteerdheid van die kloof tussen wit en swart. Die optrede van 'n enkele jeugdige paartjie kan nie eers die brug in hulle eie gemoedere met enige sekerheid of finaliteit slaan nie, ook nie die afstand wat histories tussen hulle gehandhaaf is nie - so groot dat die wit verteller na jare nie die familienaam van kennisse van 'n hele leeftyd ken nie (p. 238), dat 'n swart man verbied word om sy wit werkgewer as 'jou' aan te spreek (p. 233), dat 'n swart bywoner "lone net bokant die hongervlak" (p. 224) kry en na 33 jaar diens as 'n arm man weggestuur word.

Dat die verteller moeder Iris wydsbeen op 'n haan op 'n wolk, en Hendrik lomp en met sy kerkpak in die water voorstel, dui op 'n verwerping deur die implisiete outeur van die negatiewe houding wat albei teen Buziwe aanslaan. Daarteenoor word Petrus (in ooreenstemming met sy Nuwe-Testamentiese naamgenoot) gesien as iemand wat in geloof op die water loop (p. 218), en sy vereenselwiging met Buziwe as 'n geloofsdaad, met implikasies vir die toekoms. Dat hy haar goedkoop seksuele omgang met 'n wit luitenant gedurende 'n landbouskou verfoei, stel homself bokant so ' $n$ daad en berei op die wyse van die verhaalkuns die weg voor vir 'n gebalanseerde nuwe bedeling.

Met hierdie kontras bewerkstellig die outeur die soort appẻl wat Appiah aan die postmodernistiese kuns toedig. Die teenstelling stel egter ook die afstand voor tussen twee houdings wat merkbaar is, respektiewelik by 'n patriargale (hier Hendrik èn Iris) en 'n volgende geslag (hier Petrus), wat 'n kenmerk van die Ouer Afrikaanse plaasroman is. Kannemeysr (1988:115, 116) wys so 'n konflik/ vervreemding tussen generasies uit in Langs die grootpad (1928) en Laat vrugte (1939) van C.M. van den Heever. As 'n mens die kontras in menseverhoudinge 
tussen Petrus en Hendrik Steenekamp met die afstand in generasies by Van den Heever vergelyk, kan dit gesien word as ' $n$ trek wat sy oorsprong in die plaasroman het en wat in die postkoloniale literatuur voortgesit word.

Waar die voorstelling van jeugdige samespel in Foxtrot van die vleiseters 'n flits van vernuwing in die verhouding tussen wit en swart in die Suid-Afrikaanse samelewing bied, is dit in Etienne van Heerden se roman Die stoetmeester (1993) professionaliteit wat 'n vonk van toenadering tussen persone van verskillende ras en geslag laat spring. Siener, die hoofkarakter en die belangrikste verteller in die roman, tree op as prokureur vir die swart vrouedokter, Ayanda Thandi en haar vader, moontlik omdat hy hulle politieke affiniteit deel of miskien omdat hy bekend is vir sy hulp aan minderbevoorregte swart mense. Die haplografiese aanbod van sy misterieuse dood, waaroor hy uiteraard nie self kan verslag doen nie, kan gelees word as 'n strategie om die (byna) onmoontlikheid van die verbreking van tradisionele rassegrense en die slaan van 'n brug tussen swart en wit voor te stel.

Die leser word gelaat met die ope vraag of Siener moes boet vir sy deurbreek van die tradisionele grens tussen wit en swart en of hy soos 'n "floubok" swig onder die gewig van die las wat hy as baanbreker dra. Of stel Siener se dood maar net die bedreiging van die Afrikaner in 'n toekomstige bedeling voor? In ooreenstemming met die postmodemistiese siening van die werklikheid as misterie, word hierdie moontlikhede oopgelaat.

Hierdie 'openheid' word egter gekwalifiseer deur die mistieke teenwoordigheid van die gestorwe Siener in die slot, asook die band tussen die swart vrou en die wit vrou. Hulle bly gebind deur die liefde vir en van Siener, hulle gemeenskaplike liefde vir die plaas met sy stroom, maar ook deur hulle instelling teenoor die lewe: "Hoop is 'n instink" (p. 325).

\section{Verkenning van 'n nuwe sosiale bedeling}

Dit is opvallend dat die romans wat hier bespreek is, min klem lê op die geweldsaspek van die Suid-Afrikaanse gemeenskapslewe, soos onder andere uit die hantering van die dood van Siener blyk. Tipies van die vertelhouding is die lighartige toon daarvan - sy dit dan ook soms, soos in Suidpunt-jazz van Letoit, 'n swart humor oor die verskille wat daar bestaan. Flitse van 'n uitreik na die 'ander' groep en deernis vir 'n medemens in nood is 'n gemeenskaplike trek van hierdie romans wat in hierdie artikel bespreek is: In Juffrou Sophia vlug vorentoe word dit geknoop aan 'n sterk motief van versoening. In die werk van Venter is die kontras tussen kolonialisme en vernuwing wat menseverhoudings betref, die skerpste omlyn, terwyl Van Heerden 'n balans bereik tussen die negatiewe (die 'duister' dood van Siener) en die positiewe ('versoening' tussen die vroue 
van uiteenlopende kulture wat die naaste aan hom gestaan het). Die 'aftreksom' wat uiteindelik van hierdie groep romans gemaak kan word, is nie die redundante van kontraste uit 'n koloniale verlede nie maar die distinktiwiteit van flitse van openheid tot "wisselwerking met al die ander volkere en bevolkingsgroepe wat altyd saam met ons die land sal deel", soos Berta Smit (p. 94) die ligter kant van die (gemeenskaplike) scenario waarin hierdie romans ontstaan het en wat daarin verwerk word, voorstel.

\section{Bibliografie}

Appiah, Kwame Anthony. 1991. Is the Post- in Postmodernism the Post- in Postcolonial? Critical Inquiry, 17(2):336-357, Winter.

Danto, A. 1985. Narration and knowledge. New York : Columbia University Press

Derrida, Jacques. 1976. Of grammatology, Trans. G. Spivak. Baltimore : Johns Hopkins University Press.

Dillard, Annie. 1982. Living by fiction. New York : Harper \& Row.

Gerwel, G.J. 1983. Literatuur en apartheid: konsepsies van 'gekleurdes' in die Afrikaanse roman tot 1948. Kasselsvlei : Kampen.

Grundlingh, L.W.F. 1989. Kleio se verlate ou osse trek nog met 1938 se waens. Aambeeld, $17(2): 31-33$, Nov.

Heyns, Michiel. 1994. Overtaken by History? Obsolescence-anxiety in André Brink's 'An Act of Terror' and Etienne van Heerden's 'Casspirs and Campari's'. English Academy Review, 11:62-72, Dec.

Hutcheon, Linda. 1988. A poetics of postmodernism: history, theory, fiction. New York Routledge.

Kannemeyer, J.C. 1988. Die Afrikuanse litcratuur 1652-1987. Pretoria : Academica

Letoit, André. 1989. Suidpumt-jazz. Pretoria : HAUM-Literêr.

Louw, Anna M. 1991. Wolftyd. Kaapstad : Tafelberg.

Miles, John. 1983. Blaaskans. Emmarentia : Taurus.

Smit, Berta. 1993. Juffrou Sophia vlug vorentoe. Strand : Quellerie.

Steenberg, D.H. 1991. Postmodernistiese roman en konteks - die korrelasie tussen romanteks, literêre stroming en tydgewrig van ' $n$ veranderende Suid-Afrika, met besondere verwysing na drie romans. SAVAL Conference Papers XI, April 1991, Vanderbijlpark. p. 26-35.

Steenberg, D.H. 1996. Postmodernist prose remoulding South African history. In: De Faria, Neide (ed.) Proceedings of the XIXth triennial Congress of the International Federation for Modern languages and Literatures, August 1993. Brasilia. p. 187-192.

Van der Vyver, Marita. 1992. Griet skryf 'n sprokie. Kaapstad : Tafelberg.

Van Heerden, Etienne. 1993. Die stoetmeester. Kaapstad : Tafelberg.

Van Zyl, Susan. 1993. Symptoms, artworks and limits of narrative. Tydskrıf vir Literatuurwetenskap, 9(3/4):235-249.

Venter, Eben. 1993. Foxtrot van die vleiseters. Kaapstad : Tafelberg.

Waugh, Patricia. 1992. Practising postmodernism reading modernism. London : Edward Arnold. 